\title{
Nutritive values of passion fruit (Passiflora Species) seeds and its role in human health
}

\begin{abstract}
This study focused on proximate composition and mineral content of edible seeds of three Passiflora species; P. edulis (Purple), P. quadrangularis and P. maliformis. The moisture content ranged $9.18 \pm 0.34 \%$ in P. edulis (Purple) to $11.09 \pm 0.40 \%$ in P. quadrangularis, and the ash content was higher in P. quadrangularis $(2.35 \pm 0.13 \%)$. Among the Passiflora seeds, $\mathrm{P}$. edulis (Purple) possessed higher protein, $12.71 \pm 0.10 \%$ and total dietary fiber, $43.76 \pm 0.64 \%$ with $72-74 \%$ major fiber fraction of insoluble dietary fiber. The lipid content of $29.65 \pm 0.41 \%$ also was higher in P. edulis (Purple) indicating that the seed was rich in oil content. Passiflora quadrangularis possessed a higher ash content which constitutes minerals such as sodium, $5.508 \pm 5.465 \mathrm{mg}$ g-1 ; magnesium, $1.975 \pm 1.443 \mathrm{mg} \mathrm{g}-1$; calcium, $2.363 \pm 3.269 \mathrm{mg} \mathrm{g}-1$, and potassium, $2.425 \pm 2.500 \mathrm{mg}$ g-1 that plays a prominent role in human health. Based on ordination with Principal component analyses (PCA), the Passiflora seeds properties when compared with maize, oats, flaxseed, sesame, soybean, almond, groundnut, sunflower and pumpkin, Passiflora plant seeds formed an independent group correlated with variables, i.e., fiber, sodium, and zinc. By-products from Passiflora seeds can be used for pharmaceutical and nutraceutical purposes.
\end{abstract}

Keyword: By-products; Insoluble dietary fiber; Mineral content; Passiflora seeds; Utilization. 